\title{
O INTERROGATÓRIO POR VIDEOCONFERÊNCIA NO PROCESSO PENAL BRASILEIRO
}

\author{
Dissertação de Mestrado
}

Orientador: Professor Doutor José Raul Gavião de Almeida

Faculdade de Direito da Universidade de São Paulo

São Paulo

Janeiro, 2014 


\section{RESUMO}

Os avanços tecnológicos trouxeram inovação a vários campos de conhecimento, incluindo o Direito. Neste contexto, debatemos o uso dos meios eletrônicos para a realização de atos processuais criminais, seguindo-se o exemplo de outros setores da Justiça. A lei $n^{o}$ 11.900/09 modificou algumas previsões do Código de Processo Penal e regulamentou o uso do sistema de videoconferência no interrogatório do réu preso. Contudo, suas determinações ainda provocam discussão na doutrina e jurisprudência, no tocante, especialmente, aos direitos individuais do acusado garantidos constitucionalmente e às dificuldades que o Poder Judiciário ainda enfrenta quando se trata de dinamizar o andamento dos processos. 


\begin{abstract}
Technological advances have brought innovation to various fields of knowledge, including the study of Law. In this context, we debate the use of electronic means for the accomplishment of criminal proceeding acts, following the example of other sectors of Justice. The law n. 11.900/09 changed some provisions of the Criminal Code and regulated the use of the videoconference system in the arrested defendant's hearing. However, its provisions still raises discussion in the doctrine and jurisprudence, regardins, specially, to the accused's individual rights constitucionally granted as well as to the difficulty the Jucidiciary Power stills deals with when it comes to making the procedures in this area more dynamic.
\end{abstract}




\section{SUMÁRIO}

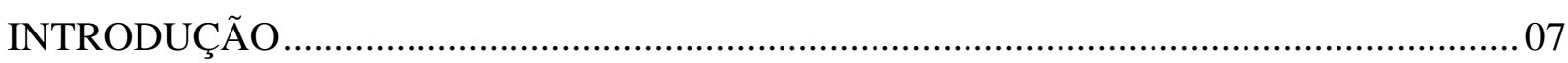

CAPÍTULO 1 - FUNDAMENTO CONSTITUCIONAL DO INTERROGATÓRIO .............. 08

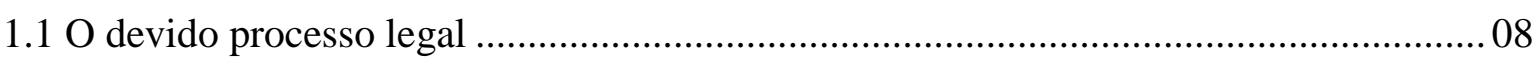

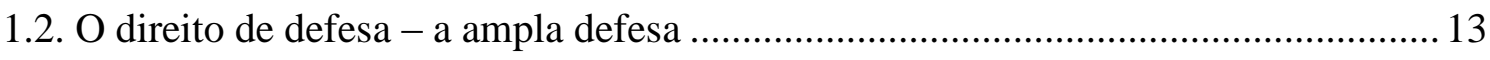

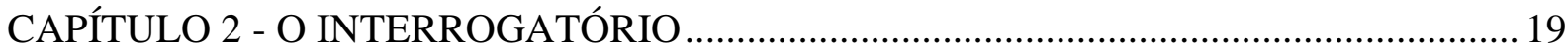

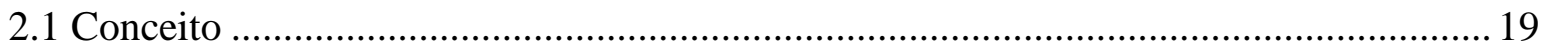

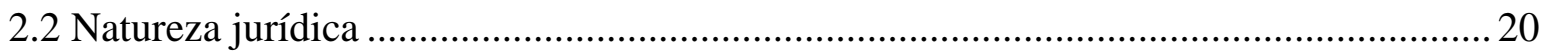

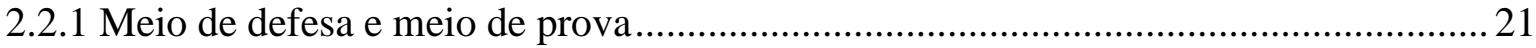

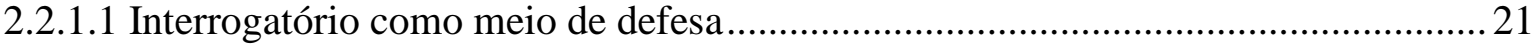

2.2.1.2 Interrogatório como meio de prova e, acidentalmente, meio de defesa .................. 23

2.2.1.3 Interrogatório como meio de defesa e, secundariamente, meio de prova ................ 23

2.2.1.4 Interrogatório como meio de defesa e meio de prova .......................................... 24

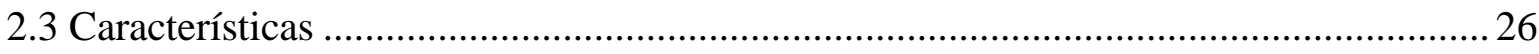

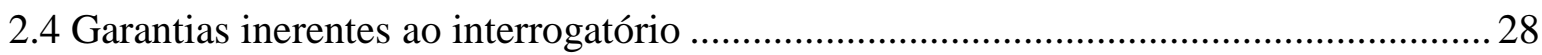

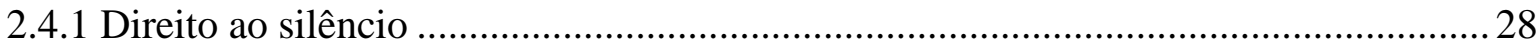

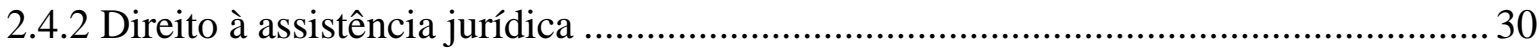

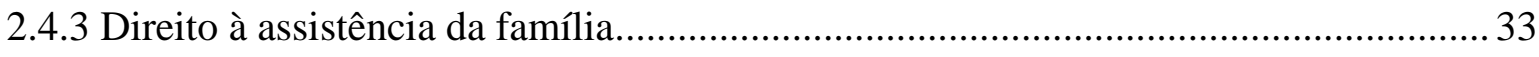

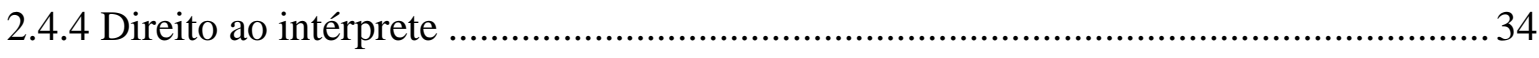

CAPÍTULO 3 - O INTERROGATÓRIO POR VIDEOCONFERÊNCIA................................ 35

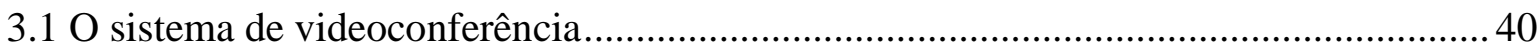

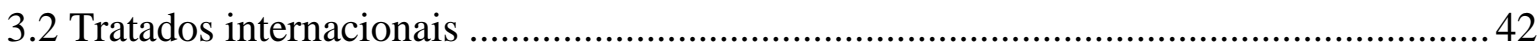

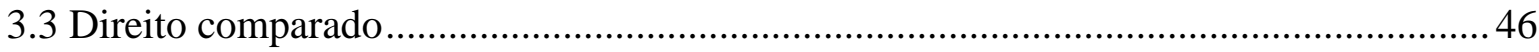

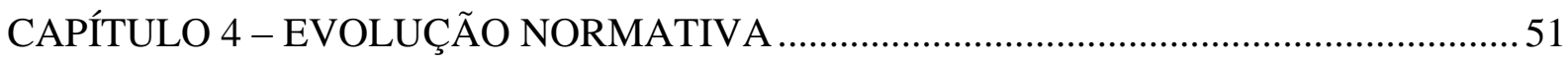

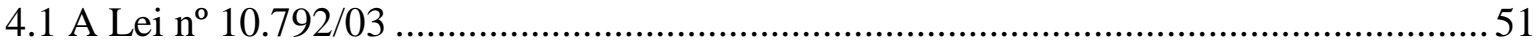

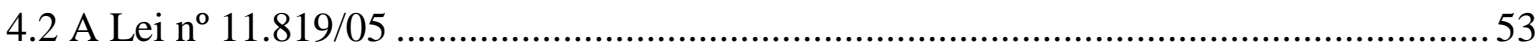

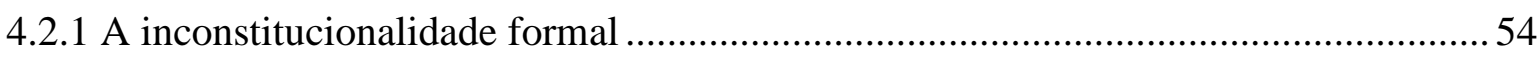

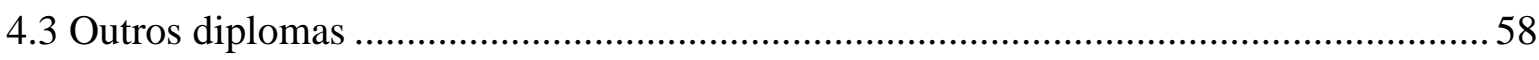

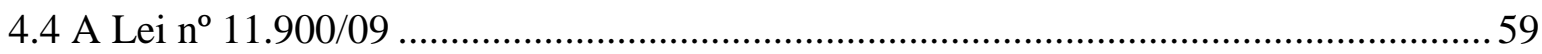

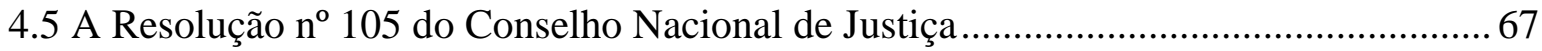

4.6 O PLS n ${ }^{\circ}$ 156/09 e o interrogatório por videoconferência ............................................. 69 


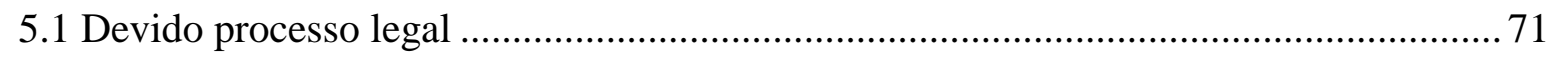

5.1.1 A polêmica em torno da expressão "comparecer" .................................................. 71

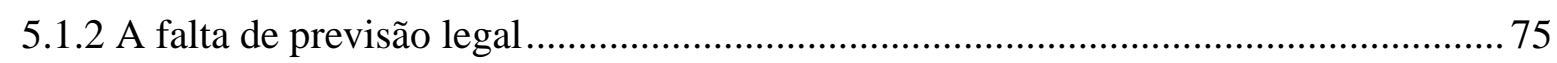

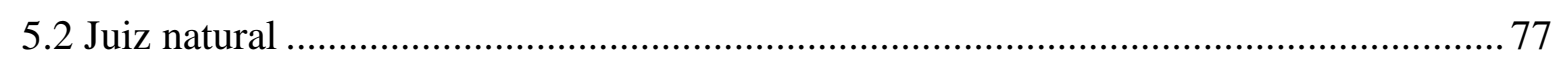

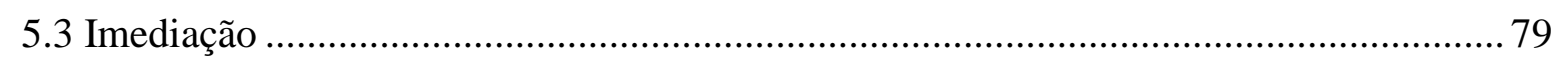

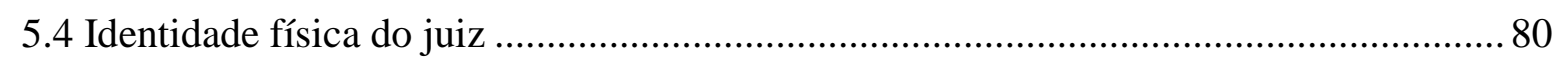

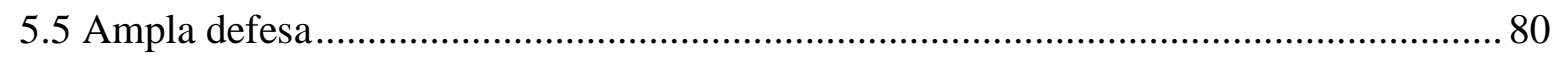

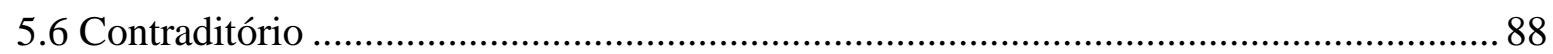

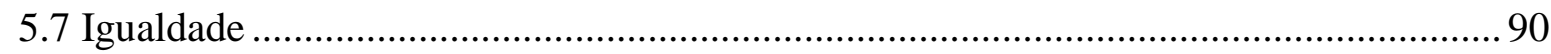

5.7.1 Posicionamento intermediário - o princípio da proporcionalidade ........................... 91

5.7.1.1 Pressupostos: legalidade e justificação constitucional ............................................. 93

5.7.1.2 Requisitos extrínsecos: judicialidade e motivação............................................... 94

5.7.1.3 Requisitos intrínsecos: adequação, necessidade e proporcionalidade em sentido

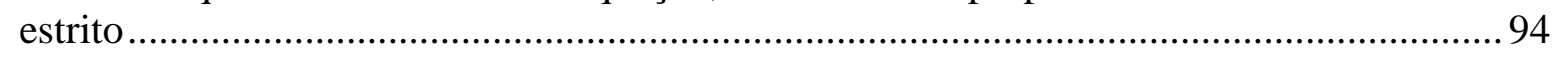

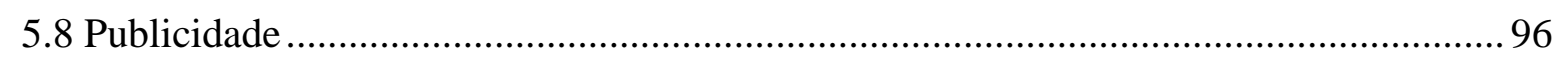

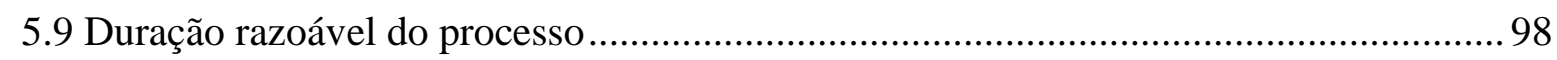

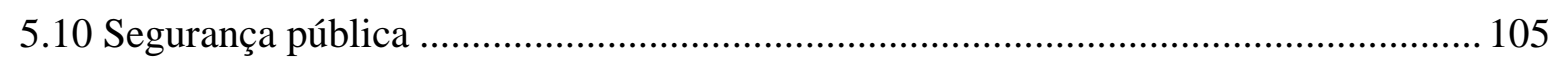

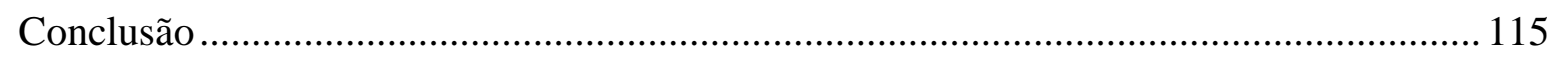

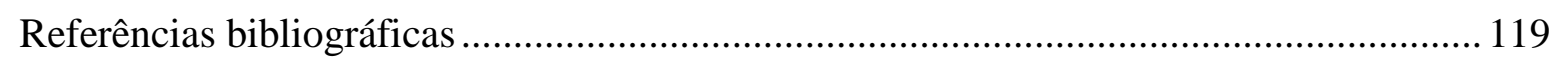




\section{INTRODUÇÃO}

Este trabalho tem por objetivo analisar a realização do interrogatório através de videoconferência no processo penal brasileiro, à luz dos princípios e garantias constitucionais inerentes a este ato processual, tais como o devido processo legal, a ampla defesa, o contraditório, a publicidade, a duração razoável do processo, entre outros.

O tema reveste-se de extrema importância em função de três principais aspectos, aqui mencionados. Primeiramente, por envolver garantias fundamentais do réu, em especial, a garantia à ampla defesa. Em segundo lugar, por ser um assunto de relevância atual, que ainda provoca debates e que começou recentemente a sofrer tentativas de regulamentação por parte do legislador. Finalmente, trata-se de um dos temas de direito que mais visivelmente atravessam as paredes dos presídios e tribunais e atingem a sociedade, que teme possíveis consequências dos transportes de presos dos estabelecimentos penais para os fóruns e, por vezes, considera avultante e mal empregada a quantia despendida para tais locomoções.

Analisar-se-á a experiência no âmbito internacional da aplicação do sistema da videoconferência, que tem se mostrado positiva, tendo alguns países adotado-a apenas para o depoimento de testemunhas e peritos, enquanto outros, regulamentado o interrogatório virtual, como os Estados Unidos e a Itália. Ademais, será observado o tratamento conferido ao tema por tratados e convenções internacionais, como no caso da ONU, por exemplo, que incentiva a adoção e regulamentação do procedimento, efetivo no combate a crimes transacionais, nos textos das Convenções de Mérida e Palermo.

Confrontar-se-ão os argumentos expostos pelas correntes favorável e contrária à realização do interrogatório por videoconferência que, em sua maioria, referem-se a garantias constitucionais. Aqui, talvez o ponto mais crítico da controvérsia seja a violação ou não à garantia do réu à ampla defesa, já que um de seus componentes, a autodefesa, é o fundamento de existência do interrogatório. 


\section{CONCLUSÃo}

É cediço que o Judiciário não pode se manter inerte enquanto tudo se desenvolve à sua volta, sob o risco de um efetivo e progressivo descompasso entre demanda e prestação jurisdicional. A realização do interrogatório por videoconferência surge como uma solução capaz de dirimir problemas relacionados à segurança pública e de conceder efetividade ao princípio da economia processual e à garantia constitucional da duração razoável do processo.

Tal modernização, porém, não poderá vir a qualquer custo, restringindo-se direitos e garantias fundamentais em benefício de vantagens econômicas. A questão não pode ser reduzida a esta contraposição de interesses da sociedade e do réu. Fez-se necessário o estudo da proposta principalmente sob a ótica deste, ressaltando-se os benefícios que a tecnologia lhe proporcionará.

$\mathrm{O}$ processo penal tem como seu arcabouço a $\mathrm{CF} / 88$, portanto, rege-se por princípios, direitos e garantias esculpidos no texto constitucional. A instrumentalização e efetivação desses são imprescindíveis e todos devem ser examinados como parte de um conjunto sistêmico, sob pena de se perderem e não se alcançar o objetivo da proteção, ou, muitas vezes, desvirtuá-lo, resultando a garantia não mais em benefício ao réu, pois, a título de exemplo, ao mesmo tempo em que este possui a garantia a ampla defesa, igualmente lhe assegura a $\mathrm{CF} / 88$ a duração razoável do processo.

Observou-se que, aos poucos, o CPP brasileiro, de 1941, foi adequado à ordem constitucional democrática vigente no país desde o fim do período ditatorial militar. Como destaque, nota-se o tratamento dispensado às garantias do acusado em processo penal.

Além do deslocamento de seu interrogatório para o fim da audiência agora una de instrução e julgamento, após a oitiva das vítimas, testemunhas, peritos, acareações e 
reconhecimento de pessoas e coisas (Leis $n^{\circ} 11.689 / 08$ e 11.719/08), a garantia ao silêncio do acusado foi reforçada, na medida em que a Lei $\mathrm{n}^{\circ}$ 10.792/03 inseriu previsão expressa no CPP de que o acusado será advertido sobre seu direito de permanecer calado e que isto não importará em confissão, não podendo ser valorado em prejuízo à sua defesa. Ademais, foi assegurado seu direito de entrevista prévia com o defensor, cuja presença se firmou como obrigatória no ato do interrogatório.

Como visto no decorrer da exposição, entendemos que a realização do interrogatório por videoconferência não viola o devido processo penal e as garantias a ele inerentes, como a ampla defesa, o contraditório, a igualdade, entre outras, e por vezes as amplia, como no caso da publicidade, da identidade física do juiz e da duração razoável do processo, por exemplo.

Existindo lei que preveja a realização da prática (como atualmente existe a Lei $\mathrm{n}^{\mathrm{o}} 11.900 / 09$, que veio suprir a falta de legislação federal que tratasse do tema, por se tratar de matéria processual e, não, procedimental), ao acusado é assegurada a comunicação plena entre ele, o juiz e seus advogados, quer seja o que se encontre no estabelecimento penal ou o que estiver no fórum, ocasião em que a comunicação se dará por meio de linhas de telefone seguras.

Resguardado e fiscalizado o ambiente de onde o réu deporá, este poderá exercer de maneira ampla sua defesa, mesmo não estando fisicamente à frente do magistrado, o qual entendemos que não necessita observar "ao vivo" suas expressões faciais para julgá-lo.

Igualmente, poderá o acusado participar da produção de toda a prova produzida na audiência. Aliás, terá sua participação aumentada no que diz respeito à oitiva de certas testemunhas, pois, antes do advento da Lei $\mathrm{n}^{\circ} 11.900 / 09$, era determinado que o réu fosse retirado da sala caso aquela não pudesse depor por videoconferência. 
A publicidade do ato não será restringida, pois a audiência poderá ser acompanhada tanto do fórum quanto do estabelecimento prisional, devendo ser observada, sempre, a necessidade de maiores medidas de segurança relativas ao trânsito de pessoas neste local.

Não há que se olvidar que uma das vantagens da utilização da videoconferência é a economia que esta proporciona aos cofres públicos, principalmente no tocante à oitiva de réus que exigem reforço de escolta, com a elaboração de operações especiais, as quais demandam uma maior quantidade de recursos humanos e financeiros. Por consequência, a segurança pública é resguardada, já que se evita o risco de fugas e trocas de tiros durante o trajeto.

Ainda, é inegável que o aparato tecnológico propicia maior agilidade do trâmite processual, pois, além de dispensar o tempo destinado ao deslocamento do preso, evita-se que as audiências sejam adiadas em razão dos problemas diários que ocorrem em relação à requisição dos acusados e aos veículos que os transportam aos fóruns. Aos acusados é garantido constitucionalmente que seus processos sejam julgados em tempo razoável.

Ademais, o princípio da identidade física é reforçado na medida em que aproxima o julgador do réu que se encontra em local distante.

A utilização da tecnologia no processo penal é uma tendência mundial inevitável, ao nosso ver, ainda que seja prevista, na maioria dos países, em caráter excepcional no que se refere ao interrogatório do acusado, tratando-se, normalmente, de casos de presos considerados perigosos e de crimes graves, como os praticados por organizações criminosas, seja em caráter nacional ou internacional.

Entende-se correta a previsão de caráter excepcional conferida pela Lei $n^{\circ}$ 11.900/09, neste momento, à realização do interrogatório por videoconferência, em função do caloroso debate provocado pelo tema. Talvez agora, com a prática legalizada e 
reiterada, mesmo que em situações predeterminadas pela lei, perca-se o temor da aplicação deste tipo de tecnologia ao processo, fazendo com que, talvez, no futuro, estudados e reconhecidos os benefícios de tal ato, a prática se dissemine no tocante aos acusados em processo penal, resultando em benefício destes e da sociedade. 


\section{REFERÊNCIAS BIBLIOGRÁFICAS}

ALMEIDA, Joaquim Canuto Mendes de. A Contrariedade na Instrução Criminal. Tese de livre docência apresentada na Faculdade de Direito da Universidade de São Paulo. São Paulo, 1937.

ALMEIDA, José Raul Gavião de. O interrogatório à distância. Tese de doutorado apresentada na Faculdade de Direito da Universidade de São Paulo. São Paulo, 2000.

ARANHA, Adalberto José Q. T. De Camargo. Da prova no processo penal. 7. ed. rev. e atual. São Paulo: Saraiva, 2008.

ARAS, Vladimir. $O \quad$ teleinterrogatório no Brasil. $\quad$ Disponível http://jus2.uol.com.br/doutrina/texto.asp?id=3632, acessado em 15.07.2013.

Teleinterrogatório não elimina nenhuma garantia processual, disponível em http://www.conjur.com.br/2004-set-28/teleinterrogatorio_nao_elimina_nenhuma_garantia_processual, acessado em 25.05.2013.

Videoconferência, persecução criminal e direitos humanos. In MOREIRA, Rômulo de Andrade. Leituras complementares de processo penal. Salvador: Editora Podivm, 2008.

ARRUDA, José Jobson de; PILETTI, Nelson. Toda a História - História Geral e História do Brasil, 11. ed. São Paulo: Editora Ática, 2002.

BADARÓ, Gustavo Henrique Righi Ivahy. A Lei Estadual $\mathrm{n}^{\circ} 11.819$, de 05/01/05 e o interrogatório por videoconferência - Primeiras impressões. Boletim IBCCRIM, ano 12, nº 148, São Paulo, mar/2005.

Processo Penal. Rio de Janeiro: Elsevier, 2012.

BARROS, Marco Antônio de. A busca da verdade no processo penal. São Paulo: RT, 2010.

; ROMÃO, César Eduardo Lavoura, Internet e videoconferência no processo penal, disponível em http://www2.cjf.jus.br/ojs2/index.php/cej/article/viewArticle/707, acessado em 18.08.2013.

BAUMAN, Zygmunt. Modernidade Líquida. Tradução: Plínio Dentzien, Rio de Janeiro: Zahar, 2001.

BEDÊ JÚNIOR, Américo; SENNA, Gustavo. Princípios do Processo Penal: entre o garantismo e a efetividade da sanção. São Paulo: RT, 2009.

BEZERRA, Bruno Gurgel. A aceitação do interrogatório por videoconferência no Brasil. Disponível em http://www.iuspedia.com.br, acessado em 20.04.2013.

BICUDO, Tatiana Viggiani. Interrogatório por videoconferência - um outro ponto de vista. Boletim IBCCrim, ano 15, nº 179, São Paulo, out/2007.

BONAVIDES, Paulo. Curso de Direito Constitucional, 7. ed., São Paulo: Malheiros, 1997. 
BRANDÃO, Edison Aparecido. Videoconferência garante cidadania à população e aos réus. Disponível em http://www.conjur.com.br/2004-out-06, acessado em 12/08/2013.

Videoconferência traz vantagens inclusive para o réu.
http://www.conjur.com.br/2008-nov-22/videoconferencia_traz_vantagens_inclusive_reu, $\begin{aligned} & \begin{array}{l}\text { Disponível } \\ \text { acessado }\end{array} \\ & \mathrm{em}\end{aligned}$ 05/08/2013.

CABETTE, Eduardo. Videoconferência: reiterando o equívoco da ordem pública. Boletim IBCCRIM: São Paulo, ano $16, \mathrm{n}^{\circ} 195$, fev/2009.

CABRAL, Maria Marta Neves. Ponderações sobre o princípio da economia processual. Disponível em http://jus2.uol.com.br/doutrina/texto.asp?id=5297, acessado em 10.09.2013.

CAPEZ, Fernando. Curso de Processo Penal. 3. ed. São Paulo: Saraiva, 1999.

_. Pontos positivos de videoconferência superam negativos. Disponível em http://www.conjur.com.br/2008-dez-04/pontos_positivos_videoconferencia_superam_negativos, acessado em 20.10.2013.

CASTELO BRANCO, Tales. Parecer sobre interrogatório on-line. Boletim IBCCRIM n ${ }^{\circ}$ 124, São Paulo, $\operatorname{mar} / 2003$.

CECARELli, Camila Franchitto. A disciplina da prova no Código de Processo Penal Português. In: FERNANDES, Antonio Scarance; ALMEIDA, José Raul Gavião de; MORAES, Maurício Zanoide de (coord.); Provas no processo penal - estudo comparado. São Paulo: Saraiva, 2011.

CHOUKR, Fauzi Hassan. Garantias constitucionais na investigação criminal. São Paulo: RT, 1995.

CINTRA, Antonio Carlos de Araujo; GRINOVER, Ada Pellegrini; DINAMARCO, Cândido Rangel. Teoria Geral do Processo. 27. ed. São Paulo: Malheiros, 2011.

CONSULTOR JURÍDICO. CNJ edita resolução que regulamenta videoconferência. Disponível em: http://www.conjur.com.br/2010-mar-10-cnj-editar-resolucao-regulamentar/videoconferencia, acessado em 24.11.2012.

_ Entidades paulistas são contra interrogatório à distância. Disponível em http://www.conjur.com.br/2002-out-23/interrogatorio_distancia_repudiado_sao_paulo, acessado em 07.08.13.

CRUZ E TUCCI, José Rogério. Garantia do processo sem dilações indevidas. In: CRUZ E TUCCI, José Rogério (coord.). Garantias constitucionais do processo civil. Homenagem aos 10 anos da Constituição Federal de 1998. São Paulo: RT, 1999.

DELMANTO, Roberto. O interrogatório por videoconferência e os direitos fundamentais do acusado no processo penal. Disponível em http://www.processocriminalpslf.com.br/o_interrogatorio.htm, acessado em 14.07.09.

DINAMARCO, Candido Rangel. A reforma da reforma. São Paulo: Malheiros, 2002.

DOTTI, René Ariel. O interrogatório à distância: um novo tipo de cerimônia degradante, disponível em http://www.senado.gov.br/web/cegraf/ril/Pdf/pdf_134/r134-23.PDF, acessado em 20.05.2013. 
D’URSO, Luiz Flavio Borges. O interrogatório on-line uma desagradável justiça virtual, disponível em http://jus2.uol.com.br/doutrina/texto.asp?id=3471, acessado em 16.06.2013.

EL DEBS, Aline. Natureza jurídica do interrogatório. Disponível em http://jus2.uol.com.br/doutrina/texto.asp?id=3123\&p=2, acessado em 10.07.2013.

FERNANDES, Antonio Scarance. A inconstitucionalidade da lei estadual sobre videoconferência. Boletim IBCCRIM, ano 12, nº147, São Paulo, fev/2005.

A mudança no tratamento do interrogatório. Boletim IBCCRIM, ano 17, no 200, São Paulo, jul/2009.

Processo penal constitucional, 2. ed., São Paulo: RT, 2000.

Reflexões sobre as noções de eficiência e garantismo no processo penal. In: FERNANDES, Antonio Scarance; ALMEIDA, José Raul Gavião de; MORAES, Maurício Zanoide de (coord.). Sigilo no processo penal: eficiência e garantismo. São Paulo: RT, 2008.

FERNANDES, Antonio Scarance; GOMES FILHO, Antonio Magalhães; GRINOVER, Ada Pellegrini. As nulidades no processo penal, 10. ed. São Paulo: RT, 2008.

FERRAJOLI, Luigi. Direito e Razão: teoria do garantismo penal. Trecho traduzido por Fauzi Hassan Choukr. 3. ed. rev. São Paulo: RT, 2010.

FIOREZE, Juliana. Videoconferência no processo penal brasileiro. Curitiba: Juruá, 2008.

FIOREZE, Juliana. Videoconferência no Processo Penal Brasileiro - Interrogatório On-line - Comentários à Lei 11.900/09 (Lei da Videoconferência). 2. ed. rev. ampl. e atual., Curitiba: Juruá, 2009, pp. 264-265.

FÓRUM Brasileiro de Segurança Pública. A videoconferência ou interrogatório on-line. Disponível em: http://www.forumseguranca.org.br/artigos/a-videoconferencia-ou-interrogatorio-on-line, acessado em 04.07.12.

GALVÃO, Danyelle da Silva. Interrogatório por videoconferência. Tese de Mestrado apresentada na Faculdade de Direito da Universidade de São Paulo. São Paulo, 2012.

GOMES, Luiz Flávio. Era digital, Justiça informatizada. Revista Síntese de Direito Penal e Processual Penal, $\mathrm{n}^{\circ}$ 17, dez./jan. 2003.

$$
\text { Justiça Colaborativa } \quad \text { Delação Premiada. Disponível em }
$$
$\overline{\mathrm{http} / / / \mathrm{lfg}}$.jusbrasil.com.br/noticias/2108608/justica-colaborativa-e-delacao-premiada, acessado em 02.09.2013.

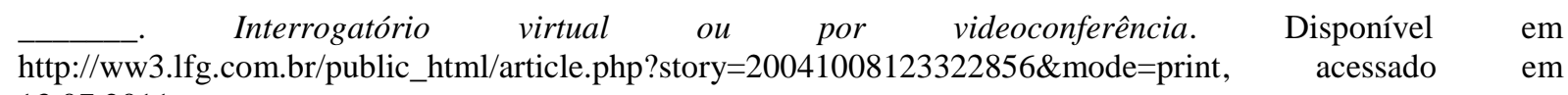
13.07.2011.

O interrogatório à distância. Boletim IBCCRIM, nº 42, jun/1996.

- $O$ uso da videoconferência na justiça brasileira. Disponível em http://ww3.lfg.com.br/public_html/article.php?story=20070315092654846\&mode=print, $\quad$ acessado em 08.05.2013.

GOMES FILHO, Antonio Magalhães. Garantismo à paulista (a propósito da videoconferência). Boletim IBCCRIM, $\mathrm{n}^{\circ} 147$, fev/2005. 
Direito à prova no processo penal, São Paulo: RT, 1997.

. Notas sobre a terminologia da prova (reflexos no processo penal brasileiro). In: Yarshell, Flávio Luiz; Moraes, Maurício Zanoide de (coord.). Estudos em homenagem à professora Ada Pellegrini Grinover. São Paulo: DPJ, 2005.

; BADARÓ, Gustavo Henrique Righi Ivahy, Prova e sucedâneos de prova no processo penal brasileiro. Revista Brasileira de Ciências Criminais, n 65, São Paulo: RT, mar/abr 2007.

GONZÁLEZ GARCÍA, Jesús María. La videoconferência como instrumento para la agilización de la justicia penal: notas sobre el modelo español. In: ROBLES GARZÓN, Juan Antonio; ORTELLIS RAMOS, Manuel (coord.). Problemas actuales del proceso iberoamericano. 1. vol. Málaga: Centro de Ediciones de la Diputación Provincial de Málaga, 2006.

GOVERNO do Estado de São Paulo. Debate sobre a videoconferência no processo penal. Disponível em: http://www.ssp.sp.gov.br/home/noticia.aspx?cod_noticia=1831, acessado em 15.10.2013.

. Sistemas de videoconferência. Disponível em: http://www.gestaopublica.sp.gov.br/ conteudo/MostraNoti.asp?par=380, acessado em 20.12.2013.

$\overline{07.05 .12}$.

Disponível em: http://www.gestaopublica.sp.gov.br/conteudo/MostraNoti.asp?par=380, acessado em

GRINOVER, Ada Pellegrini. O conteúdo da garantia do contraditório. In: Novas Tendências do Direito Processual (De acordo com a Constituição de 1998). Rio de Janeiro: Forense Universitária, 1990.

HABER, Carolina Dzimidas. A produção da prova por videoconferência. Revista Brasileira de Ciências Criminais (coord. Ana Elisa Liberatore S. Bechara) nº 82, São Paulo: RT, jan/fev 2010.

HITTERS, Juan Carlos; FAPPIANO, L. Oscar. Derecho Internacional de los derechos humanos: sistema interamericano - El pacto de San José da Costa Rica. t. II. Buenos Aires: Ediar, 1991.

IBÁÑES, Perfecto Andrés. Sobre o valor da imediação. In: Valoração da prova e sentença penal. Rio de Janeiro: Lumen Juris, 2006.

JESUS, Damásio Evangelista de. Código de Processo Penal anotado, 14. ed., São Paulo: Saraiva, 1998.

LARENZ, Karl. Derecho justo: fundamentos de ética jurídica. Trad. de Luis Díez - Picazo. Madrid: Editora Civitas AS, 1991.

LEAL, Antonio Luiz da Câmara. Comentários ao Código de Processo Penal Brasileiro. vol. III. Rio de Janeiro: Freitas Bastos, 1942.

LOPES, Alessandro Maciel. Lei paulista $n^{\circ}$ 11.819/05: norma processual ou procedimental? Disponível em http://www.ibccrim.org.br/artigo/7464-Artigo:-Lei-paulista-n\%C2\%B0-11.819-05:-norma-processual-ouprocedimental?, acessado em 31.08.2013.

LOPES JR., Aury. Direito Processual Penal e sua conformidade constitucional. 5. ed. vol. 1. Rio de Janeiro: Lumen Juris, 2010. 
. O interrogatório on-line no processo penal: entre a assepsia judiciária e o sexo virtual. Boletim IBCCRIM, $\mathrm{n}^{\circ} 154$, set/2005.

MALAN, Diogo Rudge. Direito ao Confronto no Processo Penal. Rio de Janeiro: Lumen Juris, 2009.

MARQUES, José Frederico. Elementos de direito processual penal. 2. ed. vol. II. Campinas: Millennium, 2000.

MINISTÉRIO da Justiça. Anuário Brasileiro de Segurança Pública, ano 06, 2012, disponível em http://portal.mj.gov.br/main, acessado em 17.12.2013.

MORAES, Maurício Zanoide de. Presunção de inocência no processo penal brasileiro: Análise se sua estrutura normativa para a elaboração legislativa e para a decisão judicial. Rio de Janeiro: Lumen Juris, 2010.

MOURA, Maria Thereza Rocha de Assis (coord.). As reformas no Processo Penal-As novas Leis de 2008 e os Projetos de Reforma. São Paulo: RT, 2008.

NALINI, Leandro. Visão provinciana impede a evolução da videoconferência, disponível em: http://www.conjur.com.br/2005-ago-16/visao_provinciana_impede_evolucao_videoconferencia, acessado em 10.05.2013.

NERY JÚNIOR, Nelson. Princípios do processo civil na Constituição Federal. 4. ed. São Paulo: RT, 1999.

Paulo: RT, 2009.

Princípios do processo na Constituição Federal: Processo civil, penal e administrativo. 9. ed. São

NUCCI, Guilherme de Souza. Interrogatório, confissão e direito ao silêncio no processo penal. Revista da Escola Paulista da Magistratura, ano 1, nº 2, jan/abr 1997.

NUCCI, Guilherme de Souza. Manual de processo penal e execução penal. 5. ed., São Paulo: RT, 2008.

OLIVEIRA, Ana Sofia Schimdt. O interrogatório à distância — online. Boletim IBCCRIM, nº 42, jun/1996.

OLIVEIRA, Jauvane Cavalcante de. TVS: um sistema de videoconferência, disponível em www.lncc.br/ jauvane/MSc/, acessado em 01.09.12.

OLIVEROS, Raúl Tavolari. Instituciones del nuevo proceso penal. Cuestiones y casos. Santiago: Editorial Jurídica Del Chile, 2005.

ORTIZ PRADILLO, Juan Carlos. El uso de La videoconferência en el proceso penal español. Revista Brasileira de Ciências Criminais, n 67, São Paulo: IBCCrim, jul-ago/2007.

PEDROSO, Fernando de Almeida. Processo penal - O direito de defesa: repercussão, amplitude e limites, 3. ed., São Paulo: RT, 2004.

PEREIRA, Fábio Franco; HÖHN JUNIOR, Ivo Anselmo. O combate ao crime organizado e ao terrorismo na Inglaterra. In: FERNANDES, Antonio Scarance; ALMEIDA, José Raul Gavião de; MORAES, Maurício Zanoide de (coord.). Crime organizado - aspectos processuais. São Paulo: RT, 2009.

PINTO, Ronaldo Batista. Interrogatório on line ou virtual, disponível em http://jus2.uol.com.br/doutrina/texto.asp?id=9163, acessado em 19.08.09. 
Quem sabe resistência à tecnologia não vire apenas história?, disponível em http://www.conjur.com.br/2007-fev-25/quem_sabe_resistencia_tecnologia_nao_vire_historia, acessado em 10.10.12.

PITOMBO, Cleunice Valentim Bastos; BADARÓ, Gustavo Henrique Righi Ivahy; ZILLI, Marcos Alexandre Coelho; MOURA, Maria Thereza Rocha de Assis, Publicidade, ampla defesa e contraditório no novo interrogatório judicial, Boletim IBCCRIM, ano 11, nº135, São Paulo, fev/ 2004.

PRADO, Geraldo. Sistema acusatório - A conformidade constitucional das leis processuais penais, 2. ed., Rio de Janeiro: Lumen Juris, 2001.

RANGEL, Paulo. Direito processual penal. 16. ed. rev., ampl. e atual. Rio de Janeiro: Lumen Juris, 2009.

Direito processual penal. 18. ed. rev., ampl. e atual. Rio de Janeiro: Lumen Juris, 2010.

SAAD, Marta. O direito de defesa no inquérito policial. São Paulo: RT, 2004.

SAMPAIO, Denis. Lei n. 4.554 de 02/06/05: mais uma aberração jurídica no estado do Rio de Janeiro interrogatório por videoconferência. Boletim IBCCRIM, ano13, nº154, São Paulo, set/2005.

SANTORO, Antonio Eduardo Ramires. A falaciosa identidade física do juiz no Processo Penal brasileiro. Boletim IBCCRIM, ano 21, n 245, São Paulo, abr/2013.

SCARTEZZINI, Ana Maria Goffi Flaquer. O prazo razoável para a duração dos processos e a responsabilidade do Estado pela demora na outorga da prestação jurisdicional. In: WAMBIER, Teresa Arruda Alvim et all. (Coord). Reforma do Judiciário: Primeiros ensaios críticos sobre a EC n. 45/2004. São Paulo: RT, 2005 , p. 43.

SILVA, José Afonso da. Curso de direito constitucional positivo. 9. ed., rev. e ampl., São Paulo: Malheiros, 1993.

SOUZA, João Fiorillo de. A retirada do réu da sala de audiência e o novo artigo 217 do CPP. Boletim IBCCRIM, ano 16, nº 192, São Paulo, nov/2008.

STEINER, Sylvia Helena de Figueiredo. A Convenção Americana sobre Direitos Humanos e sua integração no processo penal brasileiro. São Paulo: RT, 2000.

STF. Cooperação internacional: Justiça na era virtual, disponível em: http://www2.stf.jus.br/portalStfInternacional/cms/verConteudo.php?sigla=portalStfCooperacao_pt_br\&idConteu $\mathrm{do}=190769 \&$ modo $=\mathrm{cms}$, acessado em 12.05.2013.

TERRA. Audiência de Fernandinho Beira-Mar é adiada. Disponível em: http://noticias.terra.com.br/brasil/interna/0,,OI1452006-EI5030,00.html, acessado em: 02.01.2011.

TORNAGHI, Hélio. Curso de Processo Penal, 10. ed., São Paulo: Saraiva, 1997.

.Compêndio de Processo Penal, tomo III. Rio de Janeiro: José Konfino, 1967.

TOURINHO FILHO, Fernando da Costa. Manual de Processo Penal. 15. ed., São Paulo: Saraiva, 2012.

Processo penal, 3. vol., 28. ed., São Paulo: Saraiva, 2006.

3 vol. $20^{a}$. ed., São Paulo: Saraiva, 1998. 
TOVO, Paulo Claudio. Introdução à Principiologia do Processo Penal Brasileiro. In: Tovo, Paulo Claudio (org). Estudos de Direito Processual Penal. Porto Alegre: Livraria do Advogado, 1995.

TUCCI, Rogério Lauria. Direitos e garantias individuais no processo penal brasileiro, 3. ed., São Paulo: RT, 2009.

VAL, Ignacio Castillo. La reaparición de La víctima em El proceso penal y su relación com El Ministerio Público. Escola de Derecho de La Universidad Diego de Portales, disponível em http://www.acceso.uct.cl/congreso/docs/ignacio_castillo.doc, acessado em 20.05.12.

VEJA. Presídios de Bangu terão salas de videoconferência para interrogatório de detentos. Disponível em http://veja.abril.com.br/noticia/brasil/presidios-de-bangu-terao-salas-de-videoconferencia para-interrogatoriode-detentos, acessado em 01.12.13.

Sem estrutura, transporte de presos coloca Rio em perigo. 09.11.13. Disponível em http://veja.abril.com.br/noticia/brasil/sem-estrutura-transporte-de-presos-coloca-rio-em-perigo acessado em 01.12.13.

ZERO HORA. Presídio central da capital adotará audiências à distância, 07.04.2010. Disponível em http://www.jusbrasil.com.br/noticias/959278/presidio-central-da-capital-adotara-audiencias-a-distancia, acessado em 15.08.2011.

WEIS, Carlos. Manifestação do Conselheiro Carlos Weis referente à realização de interrogatório on-line para presos perigosos. Boletim IBCCrim n ${ }^{\circ} 120$, nov/2002.

YOKAICHIYA, Cristina Emy. A utilização de novas tecnologias no processo penal espanhol: Reflexões sobre tipicidade e atipicidade em matéria probatória. In: FERNANDES, Antonio Scarance; ALMEIDA, José Raul Gavião de; MORAES, Maurício Zanoide de (coord.); Provas no processo penal - estudo comparado, São Paulo: Saraiva, 2011. 